\title{
REVIEW
}

\section{The concept of quality of life in dementia in the different stages of the disease}

\author{
Teake P. Ettema ${ }^{1}$, Rose-Marie Dröes ${ }^{1}$, Jacomine de Lange ${ }^{2}$, \\ Marcel E. Ooms ${ }^{1}$, Gideon J. Mellenbergh ${ }^{3}$ and Miel W. Ribbe ${ }^{1}$ \\ ${ }^{1}$ Institute for Extramural Medicine (EMGO), VU Medical Center, the Netherlands \\ ${ }^{2}$ Trimbos-institute, Netherlands Institute of Mental Health and Addiction, Utrecht, the Netherlands \\ ${ }^{3}$ Department of Psychological Methods, University of Amsterdam, the Netherlands
}

ABSTRACT

In order to conceptually define quality of life (QOL) in dementia, the literature on QOL in the elderly population, in chronic disease and in dementia was studied. Dementia is a progressive, age-related, chronic condition and to avoid omissions within the dementia-specific concept of QOL, a broad orientation was the preferred approach in this literature study. Adaptation is a major outcome in studies investigating interventions aimed at improving QOL in chronic conditions, but to date, it has not been used in the definition of QOL. It is argued that adaptation is an important indication of QOL in people with chronic diseases and therefore also in dementia. Some crucial issues in assessing dementia-related QOL that are relevant to clarify the continuing debate on whether QOL, particularly in dementia, can be measured at all, are discussed. Then the following conceptual definition is offered: dementia-specific QOL is the multidimensional evaluation of the person-environment system of the individual, in terms of adaptation to the perceived consequences of the dementia.

Key words: quality of life, adaptation, dementia, elderly population, chronic disease

\section{Introduction}

Quality of life (QOL) has become a major topic of study within dementia research (Brod et al., 1999a). Alzheimer's disease or a related dementia can profoundly affect the lives of patients and their families. Without a cure, the main question in care becomes how to promote well-being and maintain an optimal QOL. But it is not always clear what QOL means. Lawton (1997) noted

Correspondence should be addressed to: Teake P. Ettema, Department of Psychiatry, VU Medisch Centrum, Valeriusplein 9, 1075 BG Amsterdam, the Netherlands. Phone: +31 (0)20 5736 517; Fax: +31 (0)20 5736 687. Email: t.ettema@vumc.nl. Received 19 Jan 2004; returned for revision 18 May 2004; revised version received 9 Jul 2004; accepted 13 Jul 2004. 
that "quality of life is defined in so many ways by so many people and, regrettably, often is not defined." Several measures for QOL in dementia were developed that reflect different conceptualizations of QOL (Logsdon and Albert, 1999). Some researchers focus on the subjective evaluation of life domains considered important by the respondent (Schölzel-Dorenbos, 2000), others use domains chosen by consensus to provide a more standardized assessment, either through self-report (Brod et al., 1999b) or through proxy reports (Logsdon et al., 1999; Rabins et al., 1999; Ready et al., 2002; Selai et al., 2001). The chosen mode of assessment depends on the population under study. For instance, in people with severe dementia, self-report measures are problematic (Lawton, 1997).

The conceptualizations of QOL also vary because most instruments were developed for patients in different stages of dementia, and the relevant life domains for QOL vary with the progression of the disease. For example, while in the early stages of dementia enjoyment of discretionary activities is relevant (Brod et al., 1999a), it no longer is in severe dementia (Hurley et al., 1992). As a consequence most instruments are unsuitable for assessing QOL in the whole range of mild to severe dementia. This presents a problem for the daily care for people with dementia and for the evaluation of interventions aimed at improving QOL, as changes in QOL with the progression of the disease are difficult to detect and assess with existing instruments.

Within the framework of the development of a new instrument to assess QOL in dementia in the different stages of the disease, the literature was studied on how the concept of QOL is defined and operationalized in the general elderly population, in chronic disease and in dementia. The aim was to define the concept of QOL in such a way that it could serve as a basis for a QOL measure in all stages of dementia. Dementia is strongly related to old age and a serious progressive chronic condition that affects all aspects of daily living. Thus the QOL domains relevant in the general elderly population and in old people with other progressive chronic diseases may also be of interest in dementia. Therefore, the starting point was the literature on QOL in the elderly population in general, followed by the literature on major progressive chronic diseases in elderly people. This approach reduced the risk of overlooking aspects of QOL in dementia.

Some general issues in QOL research, relevant to instrument development, were also identified. Finally, we present a definition of QOL in dementia that might serve as a basis for an instrument applicable in all stages of the disease.

\section{Search procedure}

To obtain relevant literature on the subject of QOL, the electronic databases of MEDLINE and PsychINFO were searched using the key words "quality of life" in combination with "elderly," "chronic disease," "dementia" or "Alzheimer's 
disease." Limits were set to publications in English, Dutch or German. This resulted in 2370 publications that were downloaded into a Procite database. This database was further searched using the key words "definition" and "model," resulting in 174 publications. The abstracts of these papers were studied with respect to relevance in defining and describing the concept of QOL and 32 papers were retained for this study. The library catalogs of the Vrije Universiteit in Amsterdam and the University of Amsterdam were searched using the same key words to find monographs on the subject, which resulted in an additional six relevant publications. Reference lists of the publications obtained were studied to identify frequently cited papers.

\section{Results of the literature study}

\section{QOL in the general elderly population}

Although interest in QOL dates as far back as Aristotle (Bowling and Windsor, 2001), the concept of QOL gained considerable attention in the 1950s and 1960s from a growing concern about the adverse consequences of unlimited economic growth (De Neeling, 1991). Besides income, other indicators of well-being were thought to be very important for a good QOL, such as education, housing, free time, and access to healthcare.

In the 1970 s the notion of the subjective evaluation of QOL gained importance. Some even considered it to be the core of the definition of QOL (Campbell et al., 1976). Not only the conditions of life but also, more importantly, the experience of those life conditions were thought to constitute QOL. The notion that an objective assessment of QOL indicators (e.g. housing conditions) can be perceived differently by different people became a major issue. In this perspective it is up to the individual to determine what should be included in assessing his or her own QOL.

George and Bearon (1980) defined QOL in four underlying dimensions: two that are objective (general health and functional status, and socioeconomic status) and two that reflect the individual's personal judgment (life satisfaction and self-esteem). They considered general health and functional status important in the older population because of the higher incidence of chronic diseases, the longer duration of recuperation from acute illness, and the high frequency with which health is mentioned by older people in surveys. Socioeconomic status was included, as income is often affected by age: resources change and may decrease after retirement. Life satisfaction was designated as the outcome of interest of the major theories of successful aging, and George and Bearon considered it might be the most crucial subjective assessment of QOL. They considered self-esteem to be a useful indicator of QOL in late life, as age-related life events and stresses may alter the self-esteem of the older person (e.g. taking part in a social service 
program may have the detrimental effect of labeling the person as "needy" or "helpless," resulting in lower self-esteem).

In 1983, Lawton initially presented the conceptual framework of "the good life" (Lawton, 1983), but later (Lawton 1991) preferred "quality of life" as the omnibus term. In 1983 his "intent was not to confuse the overall term 'quality of life' with one of the component sectors of the good life, 'perceived quality of life'” (Lawton, 1991). Contrary to George and Bearon's selectivity, Lawton's conceptual framework, which is intended as a meta-construct, presumes to account for all areas of life; for every aspect of behavior, environment and experience. He describes four sectors that comprise the concept: behavioral competence, perceived QOL, objective environment and psychological wellbeing. Behavioral competence represents the social-normative evaluation of the person's functioning in the health, cognitive, time use and social dimensions. It can be measured through performance testing or observation. Perceived QOL parallels the sector of behavioral competence in the sense that the same dimensions are evaluated by the individual. The sector of objective environment describes physical, social and economic indicators such as housing or income. A causal relationship is presumed with dimensions of behavioral competence: the indicators are a necessary condition to elicit behavior. Psychological well-being is one's subjective evaluation of the overall quality of one's inner experience and may be regarded as the ultimate outcome of a QOL model (Lawton, 1991). This conceptual framework is the basis for Lawton's definition of QOL: "the multidimensional evaluation, by both intra-personal and social-normative criteria, of the person-environment system of the individual" (Lawton, 1991). This definition can be applied to all people, but its operationalized content should be differentiated to the requirements of the researcher and the population under study. For example, the dimensions of behavioral competence should be included in any measure of QOL, but the individual being evaluated and the purpose of the evaluation should determine the appropriate indicators in each dimension (Lawton, 1991).

One decade later, Frytak (2000) stated that Lawton's work offers the most systematic attempt to conceptualize QOL in older adults. In her review on assessment of QOL in older adults, Frytak observes that many researchers currently advocate a combination of subjective and objective dimensions for QOL. The relevant QOL domains differ across the life course and this should be taken into account when choosing the appropriate instrument. Much of the gerontological literature on QOL in elderly people is concerned with clinical populations. The generally more restricted health-related QOL measures are used for frail elderly people, while health is only one of many aspects of QOL in the broader concept (Frytak, 2000). 


\section{QOL in chronic diseases}

In 1948 The World Health Organization defined health as "a state of complete physical, mental and social well-being and not merely the absence of disease or infirmity." This definition provided the conceptual framework for QOL research in medicine developed in the 1960s (Van Nieuwenhuizen, 1998) and can be considered equal to the concept of health-related QOL (Katschnig, 1997). Elkinton (1966) was the first to use the term QOL in medicine, but it was not until 1977 that the term appeared as an independent key word in the Index Medicus. The concept has been applied primarily in conditions for which there is no, or only a partial, cure, such as cancer, rheumatism and cardiovascular diseases, as patients have to live and cope with lifelong disabilities (Van Nieuwenhuizen, 1998).

A broad consensus has emerged among researchers to distinguish four domains within the QOL concept in patients with a chronic disease: somatic sensation (e.g. pain or nausea), physical and occupational function (e.g. selfcare or activity level), psychological function (e.g. anxiety or depression), and social interaction (e.g. the quality and quantity of relationships with significant others) (Schipper et al., 1996; Van Nieuwenhuizen, 1998). Specific terminology for these domains may differ between researchers. However, the consensus did not result in fewer measures of QOL in chronic diseases. On the contrary, a large number of instruments were developed (Katschnig, 1997). In their study of 67 clinical trials, Sanders et al. (1998) found that 48 trials used 62 different existing QOL measures, and 15 reported new measures.

Although in some studies generic or domain-specific (usually psychological well-being) instruments are used, most studies on QOL in chronic disease apply disease- or population-specific measures (Garratt et al., 2002; Sanders et al., 1998). Disease-specific measures are generally preferred as interventions are usually tailored for a specific population. A clear advantage of a diseasespecific questionnaire is that the items are aimed at the problems associated with that particular disease, improving responsiveness to change (Garratt et al., 2002). The disadvantage of disease-specific instruments is that comparison of QOL across different diseases cannot be made, as the instruments may differ in their conceptual approach. Based on their review of 35 intervention studies on 12 chronic diseases, De Ridder and Schreurs (2001) proposed a general framework, the stress-appraisal-coping model, as a general basis for developing interventions and measures in QOL research in chronic diseases. In this theoretical framework the challenges that people with a chronic disease face are referred to as adaptive tasks, following the work of Moos and Tsu (1977). "The notion of an adaptive task implies that chronically ill people must cope with the relevant threat or challenge and $\cdots$ maintain adequate levels of emotional, 
physical, and social functioning as expressed in measures of well-being and QOL" (De Ridder and Schreurs, 2001). Adaptive tasks considered relevant for all chronic diseases are, for example: coping with disability, preserving an emotional balance, maintaining a positive self-image and preparing for an uncertain future (Moos and Tsu, 1977). From this theoretical perspective, interventions aimed at improving QOL in patients with chronic diseases focus on effective adaptation. This means that successful adaptation can be seen as an important indication for health-related QOL.

\section{QOL in dementia}

All reports on the concept of QOL in dementia refer to the work of Lawton (1991), which can be considered an essential publication on the subject. Although some feel that people with dementia live a life of negligible quality, many researchers in the field state that a positive QOL in people with dementia has been identified.

Although Lawton's definition of QOL applies to all people, the operationalization has to be differentiated to the population under study (Lawton, 1997), for example for people with dementia. When QOL is measured within one population, the instrument has to be sensitive to the particular properties of that population. Lawton again stressed the multidimensionality of the concept and the need to assess QOL subjectively as well as objectively. In the objective sector of behavioral competence, Lawton suggests domains such as behavioral symptoms, agitation, depression, self-care abilities, meaningful time-use, social engagement, and emotional expression. In the subjective sector of perceived QOL, he suggests spirituality, satisfaction with health care, family, friends, spare time, and housing. Affect state, happiness, morale and self-esteem are examples of subjective domains in the sector of psychological well-being, while objective environmental quality may be assessed in domains such as physical safety, presence of amenities, privacy and stimulating or esthetic quality. Although aware of Lawton's work, several researchers have developed dementia-specific QOL measures with a limited number of domains, usually aimed at a particular level of disease severity. A brief outline of the measures is presented below. A full explication, including psychometric properties, falls beyond the scope of this paper. A review of QOL measures used in dementia was recently accepted for publication (Ettema et al., 2005).

In their work on the Dementia Quality of Life Instrument (D-QOL), Brod et al. (1999b) defined dementia-specific QOL as consisting of five domains: positive affect, negative affect, feelings of belonging, self-esteem, and sense of esthetics (enjoying beauty, nature and surroundings). The instrument can be administered to patients with mild to moderate dementia (MMSE > 12). 
Rabins et al. (1997; 1999) developed the Alzheimer's Disease-Related Quality of Life (ADRQL) instrument in which they specified five domains: social interaction, awareness of self, enjoyment of activities, feelings and mood, and response to surroundings. This instrument is designed to be used on all people with dementia, regardless of disease severity. It has been applied successfully in dementia residents of a long-term stay facility (mean MMSE 5.8) (GonzalezSalvador et al., 2000).

Logsdon et al. $(1999 ; 2002)$ included patient and proxy appraisal of physical condition, mood, interpersonal relationships, ability to participate in meaningful activities, and financial situation as QOL domains in their Quality of Life in Alzheimer's Disease (QOL-AD) measure. They successfully administered the questionnaire to patients with a mean MMSE of 18.1 .

In their presentation of the Cornell Brown Scale for Quality of Life in Dementia, Ready et al. (2002) propose that high QOL is indicated by the presence of positive affect, satisfactions (e.g. weight satisfaction, restful sleep), self-esteem and the absence of negative affect. Assessment of QOL with this instrument is limited to dementia patients with sufficient ability to communicate their mood, symptoms and satisfactions (promising psychometric properties were reported in a sample of 50 outpatients (mean MMSE 22.1) (Ready et al., 2002).

Volicer et al. (1999a; 1999b) provided a six-factor model of psychological well-being in advanced dementia. They recognized three continua with opposite poles of emotional state: happy-sad, engaged-withdrawn, calm-agitated. Their subject is psychological well-being and not QOL, and as a result they limit their model to the affective domain. They focus on advanced dementia and state that with the progression of dementia, the range of emotions becomes more restricted (Volicer et al., 1999b), differentiating psychological well-being in late dementia from well-being in earlier stages.

The work of Hurley et al. (1992) on the Discomfort Scale - Dementia of the Alzheimer Type (DS-DAT), for the observation of discomfort as an index of non-well-being in patients with severe dementia, is worth mentioning. It proves to be a suitable instrument for non-communicative patients (Hurley et al., 1992), and may provide useful indications for QOL in advanced dementia.

Table 1 provides an overview of the domains mentioned by the authors, including the domains proposed by Lawton (1997). Although his list is not exhaustive, it is clear that the other authors have restricted their choice of domains.

The domains overlapping or shared by most of the dementia-specific measures are: social relations or interactions, self-esteem, and mood or affect. The same domains, formulated slightly different, are also found in QOL measures for people with chronic disease, indicating that the concept of QOL used in a 


\begin{tabular}{|c|c|c|c|c|c|c|c|}
\hline $\begin{array}{l}\text { QOL } \\
\text { DOMAIN }\end{array}$ & $\begin{array}{l}\text { Lawton, } \\
1997\end{array}$ & $\begin{array}{l}\text { Brod et al., } \\
\text { 1999b }\end{array}$ & $\begin{array}{l}\text { Rabins et al., } \\
1999\end{array}$ & $\begin{array}{l}\text { Logsdon et al., } \\
1999\end{array}$ & $\begin{array}{l}\text { Ready et al., } \\
2002\end{array}$ & $\begin{array}{l}\text { Volicer } \\
\text { et al., } \\
1999 \mathrm{~b}\end{array}$ & $\begin{array}{l}\text { A D A P T I V E } \\
\text { T A S K S, } \\
\text { Dröes, } \\
1991\end{array}$ \\
\hline Affect & $\begin{array}{l}\text { Happiness } \\
\text { Agitation } \\
\text { Depression } \\
\text { Affect state } \\
\text { Emotional expression } \\
\text { Spirituality }\end{array}$ & $\begin{array}{l}\text { Positive affect } \\
\text { Negative affect } \\
\text { Sense of esthetics } \\
\text { Feelings of belonging }\end{array}$ & $\begin{array}{l}\text { Feelings and mood } \\
\text { Enjoyment of activities }\end{array}$ & Mood & $\begin{array}{l}\text { Positive affect } \\
\text { Negative affect }\end{array}$ & $\begin{array}{l}\text { Happy-sad } \\
\text { mood } \\
\text { Agitation- } \\
\text { calm } \\
\text { Engagement- } \\
\quad \text { apathy }\end{array}$ & $\begin{array}{l}\text { Maintaining an } \\
\text { emotional } \\
\text { balance }\end{array}$ \\
\hline Self-esteem & $\begin{array}{l}\text { Self-esteem } \\
\text { Life satisfaction }\end{array}$ & Self-esteem & Awareness of self & & Self-esteem & & $\begin{array}{l}\text { Maintaining a } \\
\text { positive } \\
\text { self-image }\end{array}$ \\
\hline & Morale & & & & & & $\begin{array}{l}\text { Preparing for } \\
\text { an uncertain } \\
\text { future }\end{array}$ \\
\hline $\begin{array}{l}\text { (Appraisal of) } \\
\text { physical } \\
\text { functioning }\end{array}$ & Self-care abilities & & & $\begin{array}{l}\text { Ability for activities } \\
\text { Physical condition }\end{array}$ & Satisfaction & & $\begin{array}{l}\text { Coping with } \\
\text { own disability }\end{array}$ \\
\hline Social relations & $\begin{array}{l}\text { Satisfaction with } \\
\text { family and friends }\end{array}$ & & Social interactions & Interpersonal relations & & & $\begin{array}{l}\text { Developing and } \\
\text { maintaining } \\
\text { social } \\
\text { relationships } \\
\text { Developing an } \\
\text { adequate care } \\
\text { relationship } \\
\text { with the staff }\end{array}$ \\
\hline $\begin{array}{l}\text { (Social) } \\
\quad \text { environment }\end{array}$ & $\begin{array}{l}\text { Social engagement } \\
\text { Meaningful time use } \\
\text { Physical safety } \\
\text { Presence of amenities } \\
\text { Privacy } \\
\text { Stimulating quality } \\
\text { Esthetic quality } \\
\text { Satisfaction with } \\
\text { spare time and } \\
\text { housing (institution) } \\
\text { and healthcare } \\
\text { Freedom from barriers }\end{array}$ & & $\begin{array}{l}\text { Response to } \\
\text { surroundings }\end{array}$ & $\begin{array}{l}\text { Appraisal of } \\
\text { financial situation }\end{array}$ & & & $\begin{array}{l}\text { Coping with the } \\
\text { institutional } \\
\text { environment }\end{array}$ \\
\hline Health & $\begin{array}{l}\text { Behavioral symptoms* } \\
\text { Psychiatric symptoms* }\end{array}$ & & & & & & \\
\hline
\end{tabular}

${ }^{*}$ Lawton considers specific symptoms associated with the disease to be part of QOL but stresses the need to assess QOL beyond the symptoms, and that is what disease-specific instruments aim to do. 
Table 2. Adaptive tasks for coping with dementia (Dröes, 1991; adapted from Moos and Tsu, 1977)

DEALING WITH OWN INVALIDITY

Developing an adequate care relationship with the staff

Preserving an emotional balance

Preserving a positive self-image

Preparing for an uncertain future

Developing and maintaining social relationships

Dealing with the nursing home environment

dementia-specific measure does not differ essentially from the concept in other fields of medicine.

As QOL research in dementia clearly fits in the paradigm of QOL research in chronic diseases, it is surprising that none of the authors mentioned considered adaptation to the consequences of the disease a relevant outcome in dementiarelated QOL. Yet there are numerous indications of people with dementia trying to cope with and adapt to the disease (Cotrell and Lein, 1993; Cotrell and Schulz, 1993; Kiyak and Borson, 1992). Dröes (1991) developed the adaptation-coping model for explaining and understanding psychosocial problems of people with dementia. The model is based on the coping theory of Lazarus and Folkman (1984) and the crisis theory of Moos and Tsu (1977) that distinguished seven adaptive tasks for chronic illnesses (see Table 2). Dementia causes changes in the existence of people and the stress that comes with it often leads to a disruption of the existing balance. Depending on the perceived meaning or personal appraisal of changes, the person with dementia tries to cope with them and regain a balance (Dröes and Van Tilburg, 1998; LaBarge and Trtanj, 1995). Successful coping leads to better adaptation (i.e. a state of balance) and therefore to a better QOL (Bahro et al., 1995; LaBarge and Trtanj, 1995).

The model proved to be a useful theoretical framework for designing and evaluating psychosocial interventions for people with dementia, such as psychomotor therapy (Dröes, 1991), an integrated family support program (Dröes, 1996; Dröes et al., 2000), and integrated emotion-oriented care for people with dementia in nursing homes (Finnema et al., 1998).

\section{Summary of the literature}

The names of QOL domains vary with the population under study and the purpose of the research. The four domains of somatic sensation, physical and occupational function, psychological function, and social interaction are usually encountered in different forms in health-related QOL. The disease-specific measurement of QOL seems to be the preferred way of assessment and has led to the development of a large number of instruments. The content and domains 
included in those instruments may vary, which may improve responsiveness to change but also makes comparison between various groups impossible (Katschnig, 1997). Even within a progressive disease such as dementia, the choice of domains may depend on the stage of the disease. Either objective or subjective modes of measurement are used in assessing QOL, sometimes only one, sometimes a combination of modes.

The stress-appraisal-coping model proves to be a solid theoretical framework for developing interventions in chronic diseases aimed at improving QOL, and it is used frequently, if not explicitly, then very often implicitly (De Ridder and Schreurs, 2001), with adaptation as the main outcome in intervention studies. Focusing on adaptation in the construction of QOL measures provides a promising avenue for understanding and caring for people who have a serious illness. The promising reports by Dröes et al. $(1991 ; 1996 ; 1998 ; 2000)$ suggest that adaptation as a major indication of QOL is as useful in dementia as in other chronic diseases. This is illustrated in Table 1 , which provides a view of the QOL domains relevant to dementia, and how the adaptive tasks relate to the domains. In the last section this is addressed in more detail.

\section{Discussion of general methodological issues in QOL research}

\section{A multidimensional or unidimensional concept}

QOL is generally accepted as a multidimensional concept (Lawton 1991; The WHOQOL Group, 1998), but in medicine there is a tendency to exclude general aspects, such as income or housing, when dealing with QOL and healthrelated problems (Katschnig, 1997). Research in this field uses the more limited concept of health-related QOL. In disease-specific research, this may lead to an emphasis on physical functioning (Smith et al., 1999). A factor analysis of disease-specific measures in Parkinson's disease and inflammatory bowel disease showed QOL to be one construct, in contrast to the multidimensional outcomes with generic measures (De Boer et al., 1998). For several generic instruments a second-order model of QOL has been demonstrated, with general QOL as the higher-order factor explaining the variance and covariance related to the first-order dimensions (see, for example, Hawthorne et al., 1999; Keller et al., 1998; Meuleners et al., 2003; Skevington et al., 2004). Such a model, with perceived well-being as the overall outcome, has been hypothesized for QOL in dementia as well (Jonker et al., 2001), but has not been tested.

When people are faced with a life in an institution because of the disease, a broader multidimensional concept may be preferable (Katschnig, 1997). Their living environment changes dramatically. Aspects of life such as privacy, lack of autonomy and low social support are found to be strongly related to the disorder 
that forced the person into institutional care, and must therefore be accounted for in measuring QOL.

While a single index might be preferred for evaluation purposes, authors such as Lawton (1997) and Katschnig (1997) advocate the use of a QOL profile. Of the dementia-related QOL measures mentioned above, only the D-QOL (Brod et al., 1999b) does not summate the scores on domains to one single index. Brod et al. (1999b) report moderate correlations between the subscales, leaving the hypothesis of a second-order factor of dementia-related QOL undecided. Whether calculation of a total QOL score on the other instruments is supported by the data is not demonstrated. Further research into the factor structure of dementia-related QOL is clearly needed.

\section{Subjective or normative quality of life}

In the study of QOL, it is widely accepted that an individual's perceptions of which facets of life are important can vary considerably (Carr and Higginson, 2001; George and Bearon, 1980), and many researchers consider this to be crucial in measuring QOL (Brod et al., 1999b; Lawton, 1991; 1997; Logsdon and Albert, 1999; Logsdon et al., 2002). These authors stress that subjective evaluation is an essential property of the concept, but this gives rise to confusion.

From the perspective that only the individual is able to determine what really matters in his or her life and what constitutes its quality, an idiosyncratic perception of the quality of one particular life is the logical consequence. It is a useful approach in the consulting room where the physician is confronted with a patient presenting with a serious chronic condition, and the main question is how this individual can be helped to continue living in the optimal fashion. Obviously, the patient determines what is optimal. However, in clinical research the necessity of comparable scores on any outcome measure is evident. One of the fundamental assumptions is that the dependent variable is a reliable and valid quantification of one construct. The content of the variable should not differ within and between the groups, and precisely this would happen with a strictly personal evaluation of the quality of one's own life.

From the perspective that the individual subjectively assesses a number of items on predetermined QOL domains, the measurement is subjective on a different level. For instance, in discussing what to assess in dementia, Lawton (1997) considers the following subjective domains: affect state, happiness, morale, life satisfaction and self-esteem. But here subjectivity no longer refers to the strictly intra-individual evaluation of what matters in life. It is the researcher and not the individual who determines which domains are to be assessed. In essence this is a normative approach of the concept of QOL.

The argument that QOL assessment only makes sense through asking the persons involved only logically follows when the content of the concept is perceived 
as strictly personal. Most instruments, however, use a normative approach. But within this approach they are interested in the subjective evaluation. Whether the most valid scores can be obtained through self-report is then a matter of measurement accuracy, and not a consequence of the concept.

\section{Self- or proxy-administered ratings}

As we have described, the evaluative aspect of QOL is often used as an argument in favor of patient-administered ratings. However, in some populations it may be questionable whether patients are reliable and valid informants on (aspects of) their QOL; for example, people with mental retardation, mental illness or dementia. Katschnig (1997) mentioned three fallacies that can distort the perception of a patient's QOL. The affective fallacy may distort self-reports on affect states as people tend to use their current affective state to judge how happy and satisfied they are with their lives. Inaccurate evaluations by patients who are intellectually unable to assess some life situations is referred to as cognitive fallacy. The reality distortion fallacy is constituted by hallucinations or delusions that distort the patient's perception. Based on these fallacies the validity of patient-reports on dementia-related QOL can be questioned. In dementia the cognitive fallacy would be the first to come to mind. Brod et al. (1999b) obtained adequate data with the D-QOL in 95 out of a sample of 99 people with mild to moderate dementia (MMSE > 12). Another study reported $77.5 \%$ of 213 persons with dementia (MMSE > 10) to be "interviewable" on the subject of QOL (Mozley et al., 1999). Critics, however, may insist that providing an answer does not necessarily mean that the question is understood. Brod et al. (1999b) reported that four patients with MMSE scores in the 17-21 range were not able to answer the questions. The cognitive deficit is a problem not only for self-report in advanced dementia but also for some people with mild dementia.

The alternative of proxy report can be questioned too. In general, only moderate agreement between patients and proxies is reported (Addington-Hall and Kalra, 2001), and lower levels of agreement are reported on psychosocial functioning (Sneeuw et al., 1998). While the QOL with illness might be poor in the eyes of the healthy person, a chronically ill patient may have found new meanings in life and perceive it to be valuable, which be might ignored by proxies. There is a tendency for caregivers to report lower levels of QOL than patients (Addington-Hall and Kalra, 2001), and people with a serious condition are sometimes even found to report higher levels of QOL compared to the general population (Carr and Higginson, 2001). This systematic bias is a phenomenon very often found in health-related QOL research and is referred to as the "disability paradox" (Carr and Higginson, 2001). Poor-to-moderate agreement was also found between patients with dementia and proxy reports 
using a generic health-related QOL measure, with the highest agreement on the directly observable measures of function (Novella et al., 2001). Similar results in dementia were reported by Logsdon et al. (2002). Both studies indicated a systematic bias by proxy, in the sense that they reported lower levels of (aspects of) QOL. The bias might be influenced by the burden on caregivers (Karlawish et al., 2001; Kurz et al., 2003). Despite the disagreement, other research shows that proxies are almost as good as patients in detecting changes in some QOL domains over time (Sneeuw et al., 1997). This indicates that a proxy measure, with sufficient reliability and validity, can be valuable in assessing the effect of an intervention, even if the subjects perceive their QOL on a higher level.

Agreement is better for concrete, observable aspects of life (AddingtonHall and Kalra, 2001), and can be improved by using questions that minimize respondent interpretation, judgment and opinion (Magaziner, 1997). Selection of an appropriate proxy may help (Magaziner, 1997); for example, the nurse who works only morning shifts may provide other information on a patient than a colleague working all shifts.

A particular problem in longitudinal dementia research using self-report measures is missing values in the subsequent measurements due to the progression of dementia in participants. And even if the participants still respond to the questions, their deteriorated cognitive deficit may cause their perception of the content of the questions to differ from that of the first measurement. This would be a serious threat to internal validity of the design of an experiment. A fear of missing values can be a reason to apply proxy measures (of course the choice has to be made in advance of the study).

In dementia research both modes of measurement (self-report or proxy) can be useful, as both can provide psychometrically sound data. But when patients with difficulty in understanding the questions, for example as a result of severe dementia, are included, the application of proxy measures may be preferred.

\section{Differentiating the health domain of QOL from pathology}

Another issue to be faced is the possible association between QOL and severity of dementia. When the QOL is assessed in the broad sense as proposed by Lawton (1997), there is a risk of confounding disability caused by the dementia with QOL. This problem parallels the disability paradox: symptoms only lower the QOL when they bother the patient. The mere presence of symptoms (perhaps hard to imagine for the healthy theorist) is a necessary, but not sufficient, condition to conclude a loss of health-related QOL. Operationalization of QOL in terms of adaptation can offer a solution to this problem. 


\section{Conclusion}

As the focus of interest lies in the improvement of the well-being of people with dementia, a definition of QOL should reflect adaptation (i.e. a state of balance) to all domains of life affected by the disease. It should also include affect, self-esteem, physical functioning, social relationships and environment. And it should take into account the fact that as the dementia progresses, these domains are affected differently. This offers a serious challenge for measurement, as the variance in QOL due to severity of dementia has to be accounted for. A multidimensional approach would be a safe starting point.

Inspection of Table 2 can be helpful in defining the concept. The broad conceptualization of Lawton is only met by the adaptive tasks described by Dröes, with the exception of the health domain. However, affected health is a necessary condition for disease-related QOL: the assumption is that symptoms of dementia affect QOL, and the question is how. But indications of discomfort, particularly in advanced dementia, can be interpreted as signs of diminishing QOL, and should not be overlooked.

The emphasis that Lawton (1991) puts on the environment is worth mentioning: he states that environment affects the person's well-being, and environments may differ. If the patient has to live in an institution, every facet of their environment will alter and might affect their QOL. Two adaptive tasks in the model of Dröes reflect this emphasis: "developing an adequate care relationship with the staff" and "coping with the institutional environment." So Lawton's mention of the person-environment system in his definition should be appreciated as very relevant.

Lawton puts forward psychological well-being as the ultimate outcome of his model of QOL. This is not disputed, but adopting the adaptation-coping framework in the model may provide a refinement. People strive for a sense of balance in their lives; it is a necessary condition for psychological well-being. Successful adaptation (i.e. being in balance) to the consequences of the disease will lead to a sense of well-being. As psychological well-being within a general concept of QOL can be defined as the level of perceived quality in all domains of life (Lawton, 1991), it could be defined within the concept of disease-related QOL as the level of adaptation to the perceived consequences of the disease.

A definition of dementia-specific QOL may now be offered: dementia-specific QOL is the multidimensional evaluation of the person-environment system of the individual, in terms of adaptation to the perceived consequences of the dementia.

This definition leaves the source of evaluation undecided: as stressed before, this is a matter of accuracy of measurement and not part of the concept. How the definition can be operationalized will be shown in work currently being 
undertaken by the authors on the development of a new dementia-specific QOL measure. It might be argued that the adaptive tasks are unsuited for severe dementia. However, striving for balance takes place at all levels of the living system (Sipsma, 2001). This still applies in the final stage, although perhaps mainly on a biological level (and even then communication with the patient remains essential) (Sipsma, 2001). We take the position that an adaptation process is always found, and should be incorporated in the definition.

For people in the later stages of the disease, or people who are unable to answer questions, it might still be possible to have proxies observe a level of adaptation on the basis of their behavior. A bedridden person with advanced dementia may show positive affect when brought into a living room, allowing them to passively enjoy the presence of other people. Someone with serious aphasia can clearly be frustrated by their impairment without being able to express this frustration verbally. The definition seems suitable for all stages of the disease, and with it the first step in the development of a dementia-specific QOL instrument has been taken.

\section{Acknowledgments}

This research was supported by grants from: ZonMw, Netherlands Organization for Health Research and Development (ZonMw 1365.0003); Novartis; De Open Ankh; De Stichting tot Steun van Christelijke Verzorging van Geestes en Zenuwzieken; Vereniging het Zonnehuis; and Stichting Cliënt en Kwaliteit.

\section{References}

Addington-Hall, J. and Kalra, L. (2001). Who should measure quality of life? British Medical fournal, 322, 1417-1420.

Bahro, M., Silber, E. and Sunderland, T. (1995). How do patients with Alzheimer's disease cope with their illness? A clinical experience report. Fournal of the American Geriatrics Society, $43,41-46$.

Bowling, A. and Windsor, J. (2001). Towards the good life: a population survey of dimensions of quality of life. Fournal of Happiness Studies, 2, 55-82.

Brod, M., Stewart, A. L. and Sands, L. (1999a). Conceptualization of quality of life in dementia. Fournal of Mental Health and Aging, 5, 7-20.

Brod, M., Stewart, A. L., Sands, L. and Walton, P. (1999b). Conceptualization and measurement of quality of life in dementia: the dementia quality of life instrument (DQoL). Gerontologist, 39, 25-35.

Campbell, A., Converse, P. E. and Rogers, W. L. (1976). Quality of Life in America. New York: Russell Sage.

Carr, A. J. and Higginson, I. J. (2001). Are quality of life measures patient-centred? British Medical fournal, 322, 1357-1360.

Cotrell, V. and Lein, L. (1993). Awareness and denial in the Alzheimer's disease victim. fournal of Gerontological Social Work, 19, 115-132. 
Cotrell, V. and Schulz, R. (1993). The perspective of the patient with Alzheimer's disease: a neglected dimension of dementia research. Gerontologist, 33, 205-211.

De Boer, A. G., Spruijt, R. J., Sprangers, M. A. and De Haes, J. C. (1998). Disease-specific quality of life: is it one construct? Quality of Life Research, 7, 135-142.

De Neeling, J. N. D. (1991). Quality of Life. Het Onderzoek naar Welzijnseffecten van Medische Behandelingen. Utrecht: Wetenschappelijke Uitgeverij Bunge.

De Ridder, D. and Schreurs, K. (2001). Developing interventions for chronically ill patients: is coping a helpful concept? Clinical Psychology Reviezw, 21, 205-240.

Dröes, R. M. (1991). In Beweging: over Psychosociale Hulpverlening aan Demente Ouderen. Utrecht: De Tijdstroom.

Dröes, R. M. (1996). Amsterdamse Ontmoetingscentra: een Nieuze Vorm van Ondersteuning voor Dementerende Mensen en Hun Verzorgers. Thesis, Amsterdam.

Dröes, R. M. and Van Tilburg, W. (1998). Kwaliteit van zorg en kwaliteit van leven bij dementie. In P. W. Huijbers and W. W. Van Santvoort (Eds.) (Conference proceedings) (p. 28.102). The Netherlands: Nederlands Instituut voor Gerontologie.

Dröes, R. M., Breebaart, E., Ettema, T. P., Van Tilburg, W. and Mellenbergh, G. J. (2000). Effect of integrated family support versus day care only on behavior and mood of patients with dementia. International Psychogeriatrics, 12, 99-115.

Elkinton, J. R. (1966). Medicine and the quality of life. Annals of Internal Medicine, 64, 711-714.

Ettema, T. P., Dröes, R. M., De Lange, J., Mellenbergh, G. J. and Ribbe, M. W. (2005). A review of quality of life instruments used in dementia. Quality of Life Research, 14, 675-686.

Finnema, E. J. et al. (1998). The design of a large-scale experimental study into the effect of emotion-oriented care of demented elderly and professional carers in nursing homes. Archives of Gerontology and Geriatrics, 26, 193-200.

Frytak, J. R. (2000). Assessment of quality of life in older adults. In R. L. Kane and R. A. Kane (Eds.) Assessing Older Persons. Measures, Meaning, and Practical Applications (pp. 200-236). Oxford: Oxford University Press.

Garratt, A., Schmidt, L., Mackintosh, A. and Fitzpatrick, R. (2002). Quality of life measurement: bibliographic study of patient assessed health outcome measures. British Medical fournal, 324, 1417.

George, L. K. and Bearon, L. B. (1980). Quality of Life in Older Persons: Meaning and Measurement. New York: Human Sciences Press, Inc.

Gonzalez-Salvador, T. et al. (2000). Quality of life in dementia patients in long-term care. International Fournal of Geriatric Psychiatry, 15, 181-189.

Hawthorne, G., Richardson, J. and Osborne, R. (1999). The Assessment of Quality of Life (AQoL) instrument: a psychometric measure of health-related quality of life. Quality of Life Research, 8, 209-224.

Hurley, A. C., Volicer, B. J., Hanrahan, P. A., Houde, S. and Volicer, L. (1992). Assessment of discomfort in advanced Alzheimer patients. Research in Nursing and Health, 15, 369-377.

Jonker, C. et al. (2001). [Quality of life and dementia. I. Model of assessment of well-being in dementia patients.] Tijdschrift voor Gerontologie en Geriatrie, 32, 252-258.

Karlawish, J. H., Casarett, D., Klocinski, J. and Clark, C. M. (2001). The relationship between caregivers' global ratings of Alzheimer's disease patients' quality of life, disease severity, and the caregiving experience. Fournal of the American Geriatrics Society, 49, 1066-1070.

Katschnig, H. (1997). How useful is the concept of quality of life in psychiatry? Current Opinion in Psychiatry, 10, 337-345.

Keller, S. D. et al. (1998). Use of structural equation modeling to test the construct validity of the SF-36 Health Survey in ten countries: results from the IQOLA Project. International Quality of Life Assessment. Fournal of Clinical Epidemiology, 51, 1179-1188. 
Kiyak, H. A. and Borson, S. (1992). Coping with chronic illness and disability. In M. G. Ory, R. P. Abeles and P. D. Lipman (Eds.) Aging, Health and Behavior (1st. ed.) pp. 141-173. Newbury Park: Sage.

Kurz, X., Scuvee-Moreau, J., Vernooij-Dassen, M. and Dresse, A. (2003). Cognitive impairment, dementia and quality of life in patients and caregivers. Acta Neurologica Belgica, 103, 24-34.

LaBarge, E. and Trtanj, F. (1995). A support group for people in the early stages of dementia of the Alzheimer type. Fournal of Applied Gerontology, 14, 289-301.

Lawton, M. P. (1983). Environment and other determinants of well-being in older people. Gerontologist, 23, 349-357.

Lawton, M. P. (1991). A multidimensional view of quality of life in frail elders. In J. E. Birren et al. (Eds.) The Concept and Measurement of Quality of Life in the Frail Elderly (pp. 3-27). San Diego: Academic Press.

Lawton, M. P. (1997). Assessing quality of life in Alzheimer disease research. Alzheimer Disease and Associated Disorders, 11, (Suppl 6), 91-99.

Lazarus, R. S. and Folkman, S. (1984). Stress, Appraisal and Coping. New York: Springer Publishing Company.

Logsdon, R. G. and Albert, S. M. (1999). Assessing quality of life in Alzheimer's disease: conceptual and methodological issues. Fournal of Mental Health and Aging, 5, 3-6.

Logsdon, R. G., Gibbons, L. E., McCurry, S. M. and Teri, L. (1999). Quality of life in Alzheimer's disease: patient and caregiver reports. fournal of Mental Health and Aging, 5, 21-32.

Logsdon, R. G., Gibbons, L. E., McCurry, S. M. and Teri, L. (2002). Assessing quality of life in older adults with cognitive impairment. Psychosomatic Medicine, 64, 510-519.

Magaziner, J. (1997). Use of proxies to measure health and functional outcomes in effectiveness research in persons with Alzheimer disease and related disorders. Alzheimer Disease and Associated Disorders, 11 (Suppl 6), 168-174.

Meuleners, L. B., Lee, A. H., Binns, C. W. and Lower, A. (2003). Quality of life for adolescents: assessing measurement properties using structural equation modelling. Quality of Life Research, 12, 283-290.

Moos, R. H. and Tsu, V. D. (1977). The crisis of physical illness: an overview. In R. H. Moos (Ed.) Coping with Physical Illness. (pp. 3-21) New York: Plenum Medical Book Company.

Mozley, C. G. et al. (1999). "Not knowing where I am doesn't mean I don't know what I like": cognitive impairment and quality of life responses in elderly people. International fournal of Geriatric Psychiatry, 14, 776-783.

Novella, J. L. et al. (2001). Agreement between patients' and proxies' reports of quality of life in Alzheimer's disease. Quality of Life Research, 10, 443-452.

Rabins, P. V. and Kasper, J. D. (1997). Measuring quality of life in dementia: conceptual and practical issues. Alzheimer Disease and Associated Disorders, 11 Suppl 6, 100-104.

Rabins, P. V., Kasper, J. D., Kleinman, L., Black, B. S. and Patrick, D. L. (1999). Concepts and methods in the development of the ADRQL: an instrument for assessing health-related quality of life in persons with Alzheimer's disease. Fournal of Mental Health and Aging, 5, 33-48.

Ready, R. E., Ott, B. R., Grace, J. and Fernandez, I. (2002). The Cornell-Brown scale for quality of life in dementia. Alzheimer Disease and Associated Disorders, 16, 109-115.

Sanders, C., Egger, M., Donovan, J., Tallon, D. and Frankel, S. (1998). Reporting on quality of life in randomised controlled trials: bibliographic study. British Medical fournal, 317, 1191-1194.

Schipper, H., Clinch, J. J. and Olweny, C. L. M. (1996). Quality of life studies: definitions and conceptual issues. In B. Spilker (Ed.) Quality of Life and Pharmacoeconomics in Clinical Trials (2nd edn, pp. 11-23). Philadelphia: Lippinscott-Raven. 
Schölzel-Dorenbos, C. J. (2000). [Measurement of quality of life in patients with dementia of Alzheimer type and their caregivers: Schedule for the Evaluation of Individual Quality of Life (SEIQoL)]. Tijdschrift voor Gerontologie en Geriatrie, 31, 23-26.

Selai, C. E., Trimble, M. R., Rossor, M. N. and Harvey, R. J. (2001). Assessing quality of life in dementia: preliminary psychometric testing of the Quality Of Life Assessment Schedule (QOLAS). Neuropsychological Rehabilitation, 11, 219-243.

Sipsma, D. H. (2001). Dementie in de laatste levensfase. In F. M. J. Alkema et al. (Eds.) Dementeren: Ziekte en Zorg (pp. 192-206). Assen: Van Gorcum.

Skevington, S. M., Lotfy, M. and O'Connell, K. A. (2004). The World Health Organization's WHOQOL-BREF quality of life assessment: psychometric properties and results of the international field trial. A report from the WHOQOL group. Quality of Life Research, 13, 299-310.

Smith, K. W., Avis, N. E. and Assmann, S. F. (1999). Distinguishing between quality of life and health status in quality of life research: a meta-analysis. Quality of Life Research, 8, 447-459.

Sneeuw, K. C. et al. (1997). The use of significant others as proxy raters of the quality of life of patients with brain cancer. Medical Care, 35, 490-506.

Sneeuw, K. C. et al. (1998). Comparison of patient and proxy EORTC QLQ-C30 ratings in assessing the quality of life of cancer patients. Fournal of Clinical Epidemiology, 51, 617-631.

The WHOQOL Group (1998). Development of the World Health Organization WHOQOL-BREF quality of life assessment. Psychological Medicine, 28, 551-558.

Van Nieuwenhuizen, Ch. (1998). Quality of Life of Persons with Severe Mental Illness: an Instrument. Amsterdam: Universiteit van Amsterdam.

Volicer, L. et al. (1999a). Dimensions of decreased psychological well-being in advanced dementia. Alzheimer Disease and Associated Disorders, 13, 192-201.

Volicer, L., Hurley, A. C. and Camberg, L. (1999b). A model of psychological well-being in advanced dementia. Fournal of Mental Health and Aging, 5, 83-94. 